PAPER

\title{
Facets and determinants of quality of life in patients with recurrent high grade glioma
}

\author{
A R Giovagnoli, A Silvani, E Colombo, A Boiardi
}

J Neurol Neurosurg Psychiatry 2005;76:562-568. doi: 10.1136/jnnp.2004.036186

See end of article for authors' affiliations

.....................

Correspondence to: Dr A R Giovagnoli, Department of Neurology and Neuropathology, Carlo Besta National Neurological Institute, Via Celoria 11, 20133 Milan, Italy; rgiovagnoli@ istituto-besta.it

Received 9 January 2004 Accepted in revised form 2 August 2004

\begin{abstract}
Objectives: To assess patients with recurrent high grade brain glioma with the aim of evaluating facets of quality of life (QOL) and their association with mood, cognition, and physical performance.

Methods: Ninety four glioma patients (four groups with different duration of glioma recurrence) were compared with 24 patients with other chronic neurological diseases and 48 healthy subjects. The Functional Living Index-Cancer (FLIC) provided QOL self evaluations, and standardised scales and neuropsychological tests assessed physical performance, mood, and cognition.

Results: In glioma patients, factor analysis of the FLIC items documented five domains: Psychological well being, Role/sociability, Inner experience of disease, Isolation/sharing, and Nausea. Higher FLIC total scores were related to better cognition, physical performances, and mood, and lower grading; poorer Psychological well being and worse Inner experience of disease to depressed mood; minor Role/ sociability to worse cognitive and physical performances and higher grading; worse Nausea to longer disease duration. Compared with healthy subjects, all glioma groups were cognitively impaired and more anxious, and two groups with short duration of recurrence were also more depressed. Patients with chronic neurological diseases showed worse mood and cognitive abilities compared with healthy subjects, but performed attention tests better than glioma patients. Glioma and chronic disease patients showed similar FLIC scores and autonomy.

Conclusions: These results show that QOL of recurrent high grade glioma patients is multifaceted and determined by multiple factors. Disease severity does not necessarily eliminate the possibility of expressing personal feelings and opinions which could provide criteria for clinical decision making and psychological support.
\end{abstract}

perspective of near death surpass any intention to understand patients' QOL other than in the functional sense. Conversely, QOL evaluations including personal feelings and opinions intuitively deserve attention in such life threatening situations because they can support clinical choices in concert with patients' desires and awareness.

Comprehensive QOL observations after brain tumour recurrence may be prevented by implicit difficulties in recruiting and maintaining adequate patient samples as a result of a progressive decrease in general conditions and collaboration. Cognitive impairment affecting the patients' ability to understand and answer specific questions can consistently prevent reliable self ratings, ${ }^{27}$ and all of these problems prevent longitudinal QOL evaluations in particular.

Our study evaluated the QOL in adult patients with recurrent malignant brain glioma using self evaluations and external assessments of personal, affective, and functional aspects. The specific aims were: (1) to evaluate the subjective facets of the QOL; (2) to explore the relations between self reported QOL dimensions and physical, cognitive, and emotional functioning; and (3) to compare patients with different durations of tumour recurrence with healthy subjects and patients with other chronic disabling neurological diseases; the patients with chronic diseases were selected because they also had long lasting neurological symptoms and changes in daily autonomy and life's perspectives, although they did not share the grim prognosis of patients with glioma.

Abbreviations: ADL, Activity Daily Living; AM, Attentive Matrices; FLIC, Functional Living Index-Cancer; KPS, Karnofsky Performance Status; QOL, quality of life; RCPM, Raven's Coloured Progressive Matrices; SR, Story Recall; SRDS, Self Rating Depression Scale; STAI1/2, State Trait Anxiety Inventory $1 / 2 ;$ TMTA/B, Trail Making Test A/B scenario gives rise to an impression that, after the recurrence of a brain tumour, uncertainty, loss of hope, and the

After the recurrence of a brain tumour, the evaluation and
care of the QOL are even more important because treatments temozolamide and procarbazine ${ }^{19} 2324$ However, there have and functional parameters. In particular, little attention has been given to the personal facets and meaningful themes of 
Table 1 Subject characteristics

\begin{tabular}{|c|c|c|c|c|c|c|c|}
\hline & $\begin{array}{l}\text { All glioma } \\
\text { patients }\end{array}$ & Group I & Group II & Group III & Group IV & $\begin{array}{l}\text { Healthy } \\
\text { subjects }\end{array}$ & $\begin{array}{l}\text { Chronic disease } \\
\text { patients }\end{array}$ \\
\hline & $(n=94)$ & $(n=33)$ & $(n=30)$ & $(n=18)$ & $(n=13)$ & $(n=48)$ & $(n=24)$ \\
\hline Women & 34 & 12 & 11 & 4 & 7 & 28 & 13 \\
\hline Age & $44.49(11.19)$ & $46.69(10.79)$ & $47.10(10.27)$ & $41.11(13.53)$ & $37.53(6.79)$ & $35.52(10.31)$ & $49.29(16.57)$ \\
\hline Education & $9.99(3.78)$ & $10.24(3.55)$ & $9.76(4.15)$ & $9.44(4.04)$ & $10.61(3.30)$ & $12.58(3.44)$ & $7.75(3.04)$ \\
\hline Married & 73 & 27 & 25 & 13 & 8 & 36 & 16 \\
\hline Disease duration* & $35.84(30.36)$ & $31.66(27.10)$ & $27.80(28.12)$ & $32.88(22.35)$ & $69.07(33.90)$ & - & $81.42(86.33)$ \\
\hline Time to tumour progression* & $29.31(27.57)$ & $30.66(27.10)$ & $24.73(27.82)$ & $24.44(21.18)$ & $43.23(33.55)$ & - & - \\
\hline $\begin{array}{l}\text { Interval from recurrence to } \\
\text { evaluation* }\end{array}$ & $6.53(9.88)$ & $1(0)$ & $3.10(0.95)$ & $8.50(2.52)$ & $25.76(15.01)$ & - & - \\
\hline \multicolumn{8}{|l|}{ Grading } \\
\hline III & 51 & $15(45 \%)$ & $13(43 \%)$ & $13(72 \%)$ & $10(77 \%)$ & - & - \\
\hline IV & 43 & $18(54 \%)$ & $17(56 \%)$ & $5(28 \%)$ & $3(23 \%)$ & & \\
\hline Tumour location & & & & & & - & - \\
\hline Right anterior & 24 & 9 & 10 & 2 & 3 & & \\
\hline Right posterior & 32 & 12 & 8 & 7 & 5 & & \\
\hline Left anterior & 24 & 6 & 9 & 6 & 3 & & \\
\hline Left posterior & 14 & 6 & 3 & 3 & 2 & & \\
\hline \multicolumn{8}{|l|}{ First operation } \\
\hline Biopsy & 29 & 8 & 9 & 9 & 3 & & \\
\hline Resection & 65 & 25 & 21 & 9 & 10 & & \\
\hline Re-operations & 51 & $15(45 \%)$ & $12(40 \%)$ & 13 (72\%) & 11 (84\%) & - & - \\
\hline
\end{tabular}

\section{PATIENTS AND METHODS}

\section{Subjects}

One hundred and sixteen patients with disease recurrence after surgery, radiotherapy, and chemotherapy for malignant brain tumours participated in our study between October 1991 and February 2000. This group comprised some of the 412 inpatients with brain tumour assessed for QOL and neuropsychological performances during diagnostic and treatment courses in our neurological department. The patients were retrospectively included in our study if they satisfied the following criteria: (1) histological diagnosis of glioblastoma or anaplastic astrocytoma (World Health Organisation grades III-IV); (2) clinical and radiological evidence of disease recurrence (as revealed by magnetic resonance imaging); (3) indication for chemotherapy (Karnofsky performance status (KPS $)^{28}, \geqslant 60$ ); (4) an age of more than 14 years; (5) at least three years' schooling; (6) the absence of previous psychiatric diseases or intellectual deficits; and (7) informed consent to the evaluation.

Fifteen patients were excluded because they had different histological diagnoses (three medulloblastomas, five lymphomas, five low grade gliomas, one primitive neuro ectodermal tumour, one metastasis), and seven because they could not perform the neuropsychological tests. Of the 94 patients included in the analysis, 68 could complete the questionnaires autonomously, whereas 26 needed assistance because of attention (12 patients), language (six patients), perceptual (one patient), or movement difficulties (seven patients). In these cases, a neuropsychologist read the questionnaires and wrote the patients' responses. The patients who could not complete the questionnaires autonomously did not differ in terms of age, education, disease duration, or KPS score from the others.

The patients were divided into four groups on the basis of the time interval between tumour recurrence (as indicated by radiological evidence) and the evaluation (group I, one month; group II, two to six months; group III, six to 12 months; and group IV, > 12 months). Separate one way ANOVA showed that disease duration $(\mathrm{F}(3,90)=7.43$; $\mathrm{p}=0.0002)$ and the time interval between the recurrence and evaluation $(\mathrm{F}(3,90)=65.96 ; \mathrm{p}<0.0001)$ were significantly different in the four groups, whereas there were no differences in the time to tumour progression, age, or education. Twenty nine patients underwent biopsy and 65 patients underwent subtotal or total tumour resection at the time of diagnosis, and there were no differences between the four patient groups. Fifty one patients underwent reoperation by subtotal resection after glioma recurrence. Chi squared statistics showed that the distribution of grade III and IV gliomas $\left(\chi^{2}=5.67 ; p=0.001\right.$, with less grade IV gliomas and more grade III gliomas in groups III and IV) and patients undergoing more than one operation $\left(\chi^{2}=7.72\right.$;

Table 2 Mean scale and test scores obtained by patients with glioma and controls

\begin{tabular}{|c|c|c|c|c|c|c|c|}
\hline & All glioma patients & Group I & Group II & Group III & Group IV & Healthy subjects & $\begin{array}{l}\text { Chronic disease } \\
\text { patients }\end{array}$ \\
\hline STAII & $42.90(10.91)$ & $45.18(11.67)$ & $43.13(10.93)$ & 39.22 (8.98) & $41.69(10.96)$ & $26.95(8.05)$ & 47.08 (12.09) \\
\hline STAI2 & 42.58 (10.71) & 42.45 (10.85) & 43.83 (12.35) & 41.33 (8.67) & $41.76(9.65)$ & $29.85(9.25)$ & $42.70(10.66)$ \\
\hline SRDS & $39.08(9.25)$ & $40.63(9.43)$ & $39.56(10.49)$ & $36.83(7.86)$ & $37.15(7.35)$ & $28.41(8.23)$ & $37.41(7.65)$ \\
\hline FLIC & $105.77(23.40)$ & $103.75(22.83)$ & $103.90(26.02)$ & $108.44(22.38)$ & $111.53(21.04)$ & - & $105.45(19.49)$ \\
\hline$A D L$ & $16.73(2.49)$ & $16.90(2.51)$ & $16.60(2.66)$ & $16.44(2.59)$ & $17.00(2.12)$ & - & $17.20(1.56)$ \\
\hline KPS & 79.26 (15.67) & $80.90(14.65)$ & $75.66(14.78)$ & $80.55(18.30)$ & 81.53 (16.75) & - & - \\
\hline RCPM & $26.02(6.71)$ & $25.39(6.10)$ & $26.26(6.77)$ & $27.16(7.59)$ & $25.46(7.34)$ & 32.64 (3.34) & $26.00(5.21)$ \\
\hline AM & $41.50(13.22)$ & $42.06(13.52)$ & $39.53(12.78)$ & $40.50(14.03)$ & $46.00(12.62)$ & $57.66(2.44)$ & $50.79(6.20)$ \\
\hline TMTA & $120.64(104.40)$ & $120.21(108.48)$ & $130.13(106.20)$ & $119.66(102.44)$ & $101.23(101.65)$ & 35.77 (12.45) & $75.75(39.83)$ \\
\hline TMTB & $290.02(209.64)$ & $252.33(154.53)$ & $310.83(227.47)$ & $339.77(243.20)$ & $268.76(242.68)$ & $93.75(30.16)$ & $185.00(113.17)$ \\
\hline SR & $8.69(5.22)$ & $8.78(5.61)$ & $8.28(5.14)$ & $8.83(4.98)$ & $9.19(5.28)$ & $16.10(4.37)$ & $10.64(4.74)$ \\
\hline
\end{tabular}

ADL, Activity Daily Living; AM, Attentive Matrices; FLIC, Functional Living Index-Cancer; KPS, Karnofsky Performance Status; RCPM, Raven's Coloured Progressive Matrices; SR, Story Recall; SRDS, Self Rating Depression Scale; STAI1/2, State Trait Anxiety Inventory 1/2; TMTA/B, Trail Making Test A/B. 
$\mathrm{p}=0.005$, with more re-operations in groups III and IV) was significantly different in the four groups, but no difference was found in the distribution of tumour location, sex, or marital status (table 1). After the first surgical operation, all of the patients had undergone fractionated radiotherapy using total radiation doses of 5000-6000 Rads. Radiotherapy was performed by external beam radiation with limited fields on the enhanced area with $2 \mathrm{~cm}$ margins and a dose/fraction of 1.8-2 Gy, according to a conventional (one fraction/day) or hyperfractionated (2-3 fractions/day) protocol.

Chemotherapy had been performed during or after radiotherapy using different combinations of carbiplation, cisplatin, and etoposide in three day treatment schedules repeated for up to seven to 10 cycles, with intervals of four to five weeks. At the time of the evaluation, all of the patients were receiving steroid treatment. The controls were 48 healthy subjects recruited from our hospital staff and 24 patients with other chronic neurological diseases (chronic paraparesis, multiple sclerosis, myasthenia gravis, polyneuropathies). All control patients had chronic motor disabilities and uncertain prognosis relating to disease progression. In addition, the patients with multiple sclerosis, myasthenia gravis, or polyneuropathies faced the possibility of acute or life threatening neurological symptoms; in particular, patients with multiple sclerosis had a history of brainstem or spinal cord attacks with bulbar palsy and quadriplegia; the patients with polyneuropathies reported disturbances of autonomic functions and trunk motor palsy with respiratory failure; and the patients with myasthenia gravis experienced weakness of the pharynx, larynx, neck, and chest muscles. The patients with multiple sclerosis or chronic paraparesis also reported cognitive failures, whereas the patients with polineuropathies or myasthenia gravis complained of mental slowing, which motivated neuropsychological examination. The combination of disabilities, chronic progression, and unpredictable impairments prevented the control patients from making decisions and projects, although their diagnoses allowed more hope of survival than in those with high grade gliomas. Compared with the healthy controls, the group I and II patients with glioma and the patients with other chronic diseases were significantly older $(F(5,160)=7.36 ; \quad p<0.0001)$; the patients with other chronic diseases also had lower education levels $(\mathrm{F}(5,160)=6.55 ; \mathrm{p}<0.0001)($ table 1$)$.

\section{Self evaluation scales and neuropsychological tests}

The Functional Living Index-Cancer (FLIC), ${ }^{29}$ a visual analogue scale, was chosen for the QOL self evaluation because it had previously been well accepted by the patients and their families, and had been found to discriminate different disease stages by showing the worst level in patients with recurrent gliomas. ${ }^{9}$ A higher FLIC total score indicates a better QOL. Perceived mood was self rated using the State Trait Anxiety Inventory (STAI $1-2)^{30}$ and the Self Rating Depression Scale (SRDS), ${ }^{31}$ where higher scores indicate worse anxiety and depression. Autonomy in everyday activities was evaluated by the Activity Daily Living (ADL) scale, $^{32}$ and physical functional performance by the KPS scale $^{28}$ which provide direct indices of autonomy.

Raven's Coloured Progressive Matrices (RCPM), ${ }^{33}$ Attentive Matrices (AM), ${ }^{34}$ Trail Making Test (TMT A-B), ${ }^{35}$ and Story Recall (SR $)^{36}$ were used to assess abstract reasoning, selective attention, visuomotor coordination, divided attention, and episodic memory, respectively; higher test scores indicate better performances, except for the TMT, which provides time scores inversely associated with the level of performance. The healthy subjects completed the anxiety and depression scales, and underwent the neuropsychological tests; the patients with other chronic neurological diseases were also administered the ADL and FLIC scales (without adaptations of the contents).

\section{Data analysis}

The internal consistency of the FLIC in patients with glioma was assessed by computing Cronbach's $\alpha$ coefficient. The domains making up the FLIC structure in patients with glioma were assessed by factor analysis of the 22 FLIC items to evaluate specific associations in patients with glioma. The items were attributed to one factor on the basis of a factor loading of more than 0.40 , with the factor being identified according to an eigen value of more than 1 . A separate factor analysis was used to assess the scores of the mood, daily

\begin{tabular}{|c|c|c|c|c|c|}
\hline FLIC items & $\begin{array}{l}\text { F1: Psychological } \\
\text { well being }\end{array}$ & $\begin{array}{l}\text { F2: Role/ } \\
\text { sociability }\end{array}$ & $\begin{array}{l}\text { F3: Inner experience } \\
\text { of disease }\end{array}$ & $\begin{array}{l}\text { F4: Isolation/ } \\
\text { sharing }\end{array}$ & F5: Nausea \\
\hline 1 (depression) & 0.76 & & & & \\
\hline 2 (stress) & 0.65 & & & & \\
\hline 6 (well being) & 0.75 & & & & \\
\hline 9 (discouragement) & 0.68 & & & & \\
\hline 11 (discomfort) & 0.44 & & & & \\
\hline 21 (confidence) & 0.64 & & & & \\
\hline 22 (self-image) & 0.74 & & & & \\
\hline 4 (spare time) & & 0.67 & & & \\
\hline 7 (homework initiative) & & 0.73 & & & \\
\hline 10 (work satisfaction) & & 0.72 & & & \\
\hline 13 (daily activities) & & 0.59 & & & \\
\hline 15 (homework fulfilment) & & 0.80 & & & \\
\hline 8 (social discomfort) & & 0.34 & & & \\
\hline 3 (disease thoughts) & & & 0.75 & & \\
\hline 14 (losses due to disease) & & & 0.58 & & \\
\hline 18 (fear of future) & & & 0.65 & & \\
\hline 19 (availability to social life) & & & 0.41 & & \\
\hline 20 (discomfort owing to disease) & & & 0.61 & & \\
\hline $\begin{array}{l}12 \text { (isolation) } \\
16 \text { (sharing) }\end{array}$ & & & & $\begin{array}{l}0.74 \\
0.88\end{array}$ & \\
\hline 5 (nausea effects) & & & & & 0.82 \\
\hline 17 (nausea recurrence) & & & & & 0.80 \\
\hline $\begin{array}{l}\text { Explained variance } \\
\text { Total }=62.5 \%\end{array}$ & $34.6 \%$ & $9.2 \%$ & $7.8 \%$ & $5.8 \%$ & $5.1 \%$ \\
\hline
\end{tabular}

F1-5, factors 1-5; FLIC, Functional Living Index-Cancer. 
Table 4 Factor structure of the mood and performance scales and neuropsychological tests in patients with glioma

\begin{tabular}{llll}
\hline & F1: Cognition & F2: Mood & $\begin{array}{l}\text { F3: Physical } \\
\text { performance }\end{array}$ \\
\hline RCPM & 0.64 & & \\
AM & 0.77 & & \\
TMTA & -0.87 & & \\
TMTB & -0.85 & & \\
SR & 0.68 & 0.87 & \\
STAl1 & & 0.91 & \\
STAI2 & & 0.83 & \\
SRDS & & & 0.81 \\
KPS & & & 0.90 \\
ADL & & \\
Explained variance & $41.6 \%$ & $20.1 \%$ & $10.2 \%$ \\
Total =71.9\% & & & \\
\hline
\end{tabular}

ADL, Activity Daily Living; AM, Attentive Matrices; FI-3, factors 1-3; FLIC, Functional Living Index-Cancer; KPS, Karnofsky Performance Status; RCPM, Raven's Coloured Progressive Matrices; SRDS, Self Rating Depression Scale; SR, Story Recall; STAI1/2, State Trait Anxiety Inventory 1/2; TMTA/B, Trail Making Test A/B.

activities, and performance status scales, and the neuropsychological tests, aiming to determine the structural composition of the whole battery and to reduce the number of the independent variables included in correlation and regression analyses.

Separate Pearson's analyses assessed the correlation of the FLIC total score and factors with the mood, performance, and neuropsychological factors, age, education, disease duration, time to tumour progression, and the interval between recurrence and assessment. We used t statistics to compare patients of different sex, marital status, and tumour grading, and one way ANOVA to compare patients with different tumour locations (hemispheric left and right, anterior, and posterior). Multiple stepwise regression analyses were used to explore the influence of the above independent variables on the FLIC total score and factors. Comparisons between the patients with glioma in the different groups, the healthy subjects, and the patients with other chronic diseases were made by means of parametric ANOVA and Bonferroni's tests (for STAI, SRDS, and SR) or Kruskall-Wallis non-parametric ANOVA and Mann-Whitney tests (for FLIC, RCPM, AM, and TMT) because of the non-homogeneous variances in the test scores.

\section{RESULTS \\ QOL and neuropsychological performances in patients with glioma}

Table 2 shows the mean scale and test scores obtained by the patients with glioma, healthy subjects, and the patients with other chronic diseases. In the patients with glioma, the internal consistency of the FLIC items was expressed by a Cronbach's $\alpha$ coefficient of 0.91 . Factor analysis of the FLIC items identified five factors: Psychological well being, Role/ sociability, Inner experience of disease, Isolation/sharing, and Nausea (table 3). Factor analysis of the other scales and tests revealed three factors: Cognition, Mood, and Physical performance (table 4).

\section{Relations of self reported QOL to mood, functional aspects, and disease related variables}

Table 5 shows the results of Pearson's analyses revealing significant correlations of the FLIC total score and Psychological well being, Role/sociability, Inner experience of disease, and Nausea factors with the factors of Cognition, Mood, and Physical performance, and disease duration. The FLIC total score or factors did not correlate with time to tumour progression, the interval between recurrence and assessment, age, or education. The Isolation/sharing factor showed no correlations.

$\mathrm{T}$ statistics reveal no differences in the FLIC total score, STAI, SRDS, KPS, ADL, or neuropsychological test scores between male and female patients, or married and unmarried patients. Comparison of the patients who underwent one surgical operation and those who underwent more than one showed significant differences in disease duration $(\mathrm{t}(92)=-4.83 ; \mathrm{p}<0.001)$, time to tumour progression $(\mathrm{t}(92)=-3.90 ; \mathrm{p}<0.001)$, and the interval between recurrence and assessment $(\mathrm{t}(92)=-3.48 ; \mathrm{p}=0.001)$ because of the longer intervals in the re-operated patients. The re-operated patients were also younger $(\mathrm{t}(92)=2.42$; $p=0.01)$ and had a higher education level $(t(92)=-1.99$; $\mathrm{p}=0.05$ ) than the others, whereas there were no differences between the two groups in the QOL scales and neuropsychological test scores. The patients with grade III and IV glioma had different FLIC total scores $(\mathrm{t}(92)=2.31$; $\mathrm{p}=0.023)$, and KPS $(\mathrm{t}(92)=3.42 ; \mathrm{p}=0.001)$ and AM scores $(\mathrm{t}(92)=2.87 ; \mathrm{p}=0.005$; lower in patients with grade IV glioma); they also differed in terms of age $(\mathrm{t}(92)=-2.75 ; \mathrm{p}=0.007$; patients with grade IV glioma were older), and disease duration $(\mathrm{t}(92)=5.48 ; \mathrm{p}<0.001)$, time to tumour progression $(\mathrm{t}(92)=4.86 ; \mathrm{p}<0.001)$, and the interval between recurrence and evaluation $(\mathrm{t}(92)=2.68 ; \mathrm{p}=0.009$; longer in patients with grade IV glioma). One way ANOVA revealed no differences between the patients with different hemispheric tumour locations in terms of the QOL scales and neuropsychological test scores, or in terms of clinical variables.

Multiple stepwise regression analysis showed that the FLIC total score was significantly and positively associated with the Mood, Cognition, and Physical performance factors. Of the FLIC factors, better Psychological well being and Inner experience of disease were positively associated with the Mood factor; and Role/sociability with Cognition and the Physical performance factors. In terms of clinical variables, regression analyses showed that the FLIC total score and the Role/sociability factor were inversely associated with tumour grading, and worse Nausea was associated with longer disease duration. Isolation/sharing showed no associations (table 5).

\section{Between group comparisons}

The QOL scales and neuropsychological tests were compared between the four glioma groups belonging to different disease epochs and the two control groups. Significance was set at $p \leqslant 0.0062$ (according to Bonferroni's correction for eight pairwise comparisons for each test measure at an overall $\alpha$ error of $<0.05$ for each factor). Considering the numerical differences between patient and control groups, these comparisons had an exploratory nature, aiming to highlight emergent features of QOL in recurrent glioma groups. Between group comparisons using parametric one way ANOVA for STAIl $(\mathrm{F}(5,160)=19.49 ; \mathrm{p}<0.0001)$, STAI2 $(\mathrm{F}(5,160)=10.46 ; \mathrm{p}<0.0001)$, SRDS $(\mathrm{F}(5,160)=$ $10.21 ; \mathrm{p}<0.0001)$, and SR $(\mathrm{F}(5,160)=14.27 ; \mathrm{p}<0.0001)$, and Kruskall-Wallis ANOVA for RCPM $\left(\chi^{2}=46.19\right.$; $\mathrm{p}<0.0001)$, AM $\left(\chi^{2}=77.37 ; \mathrm{p}<0.0001\right)$, TMTA $\left(\chi^{2}=\right.$ 67.43; p $<0.0001)$, and TMTB $\left(\chi^{2}=58.05 ; \mathrm{p}<0.0001\right)$ showed significant differences in anxiety and depression scales and neuropsychological test scores. No difference was found between the patients with glioma and those with chronic disease in the FLIC or ADL scores. Post hoc tests revealed that the four glioma groups and the chronic disease group had higher state and trait anxiety levels than the healthy controls, whereas only the group I and II patients with glioma and the patients with chronic disease had higher 
Table 5 Significant results of correlation and regression analyses of the FLIC total score and factors

\begin{tabular}{|c|c|c|c|c|c|}
\hline & \multicolumn{5}{|l|}{ Independent variables } \\
\hline & Cognition & Mood & Physical performance & Disease duration & Tumour grading \\
\hline $\begin{array}{l}\text { FLIC total score } \\
\text { Psychological well being }\end{array}$ & $\begin{array}{l}r=0.26, \mathrm{p}<0.01 \\
R^{2}=0.59, \mathrm{~F}=43.15 \\
\mathrm{p}<0.0001\end{array}$ & $\begin{array}{l}r=-0.63, \mathrm{p}<0.001 \\
R^{2}=0.40, \mathrm{~F}=61.64 \\
\mathrm{p}<0.0001 \\
r=-0.58, \mathrm{p}<0.001 \\
\mathrm{R}^{2}=0.34, \mathrm{~F}=47.16 \\
\mathrm{p}<0.0001\end{array}$ & $\begin{array}{l}r=0.35, \mathrm{p}<0.001 \\
R^{2}=0.52, \mathrm{~F}=49.68 \\
\mathrm{p}<0.0001\end{array}$ & & $\begin{array}{l}R^{2}=0.05, F=5.25 \\
p=0.02\end{array}$ \\
\hline Role/sociability & $\begin{array}{l}r=0.34, \mathrm{p}<0.001 \\
R^{2}=0.39, \mathrm{~F}=25.39 \\
\mathrm{p}<0.0001\end{array}$ & & $\begin{array}{l}r=0.49, \mathrm{p}<0.001 \\
R^{2}=0.24, \mathrm{~F}=29.67 \\
\mathrm{p}<0.0001\end{array}$ & & $\begin{array}{l}R^{2}=0.07, \mathrm{~F}=6.90 \\
\mathrm{p}=0.01\end{array}$ \\
\hline $\begin{array}{l}\text { Inner experience of } \\
\text { disease }\end{array}$ & & $\begin{array}{l}r=-0.32, \mathrm{p}<0.001 \\
R^{2}=0.10, \mathrm{~F}=10.31 \\
\mathrm{p}=0.0018\end{array}$ & & & \\
\hline Nausea & & & & $\begin{array}{l}r=0.24, \mathrm{p}<0.01 \\
R^{2}=0.06, \mathrm{~F}=5.81 \\
\mathrm{p}=0.017\end{array}$ & \\
\hline
\end{tabular}

depression levels than the healthy subjects. In comparison with the healthy controls, all of the glioma groups and the chronic disease group were impaired on the RCPM, SR, AM, and TMT. In comparison with the patients with chronic diseases, the group II patients with glioma had lower AM scores. No differences were found between the glioma groups (table 6). Given the specific attention impairment of patients with glioma, a regression analysis was used to explore the association between disease duration and AM scores, including the neuropsychological test scores, STAI, SRDS, and KPS scores, age, education, and the type of first surgery as independent variables. The analysis showed a longer disease duration to be associated with better attention functioning $\left(R^{2}=0.074 ; \mathrm{F}=5.54 ; \mathrm{p}=0.021\right)$. No association was found between disease duration and the other cognitive test or scale scores or clinical variables.

\section{DISCUSSION}

Our results show that the global QOL level of patients with recurrent brain glioma (as expressed by a mean FLIC score of 104) was poorer than that previously seen in patients with stable disease (a mean FLIC score of 116), ${ }^{15}$ but not worse

Table 6 Results of comparisons of glioma patient groups and control groups

\begin{tabular}{lll}
\hline & One way ANOVA & Kruskall-Wallis ANOVA \\
\hline FLIC total score & $N S$ & NS \\
STAl1 & $F(5,160)=19.49 ;$ & \\
STAI2 & $p<0.0001^{*}$ \\
& $\mathrm{~F}(5,160)=10.46 ;$ & \\
SRDS & $\mathrm{p}<0.0001^{*}$ \\
& $\mathrm{~F}(5,160)=10.21 ;$ & \\
SR & $\mathrm{p}<0.0001 \dagger$ & \\
& $\mathrm{F}(5,160)=14.27 ;$ & \\
RCPM & $\mathrm{p}<0.0001^{*}$ & \\
AM & & $\chi^{2}=46,19 ; \mathrm{p}<0.0001 \neq$ \\
TMTA & & $\chi^{2}=77.37 ; \mathrm{p}<0.0001 \neq \S$ \\
TMTB & & $\chi^{2}=67.43 ; \mathrm{p}<0.0001 \neq$ \\
\hline
\end{tabular}

Bonferroni post hoc tests $(p<0.006)$ : *worse scores in the glioma groups I, II, III, and IV, and chronic disease group $v$ healthy subjects; †worse scores in the glioma groups I and II, and chronic disease group $v$ healthy subjects. Mann-Whitney post hoc tests $(p<0.006)$ : łworse scores in the glioma groups I, II, III, and IV, and chronic disease group $v$ healthy subjects; §worse scores in the glioma group II $v$ chronic disease group. ADL, Activity Daily Living; AM, Aftentive Matrices; FLIC, Functional Living Index-Cancer; KPS, Karnofsky Performance Status; RCPM, Raven's Coloured Progressive Matrices; SR, Story Recall; SRDS, Self Rating Depression Scale; STAI1/2, State Trait Anxiety Inventory 1/2; TMTA/B, Trail Making Test A/B. than that seen in patients with other types of cancer (a mean FLIC score of 107) ${ }^{29}$ or patients with other chronic neurological diseases (a mean FLIC score of 105). The relatively acceptable QOL level in our patients with glioma is consistent with the selection criteria of a willingness to perform neuropsychological tests and an indication for chemotherapy, which excluded serious functional impairments. In this regard, patients referred for chemotherapy because of a recurrent glioma usually have a better prognosis than untreated patients. ${ }^{37}$ On this basis, our patients were highly selected and cannot reflect the condition of seriously ill patients whose QOL can only be evaluated by means of an external assessment of functional aspects. However, in terms of disease duration, they were comparable with other patients with glioma described in the literature. ${ }^{4}$

Factor analysis of the FLIC items revealed that the self rated QOL in these patients covered five main facets: Psychological well being, Role/sociability, Inner experience of disease, Isolation/sharing, and Nausea, which parallel well known dimensions in patients with brain tumours. ${ }^{14}{ }^{38}$ The FLIC factors observed in our patients with glioma also shared the psychological, social, and nausea components described in other patients with cancer, ${ }^{29}$ although physical well being was not a separate factor. On the basis of the correlation and regression analyses, the FLIC total score proved to reflect emotional, cognitive, and functional aspects, and the FLIC factors showed good concurrent validity with respect to standardised instruments, supporting the results of the factor analysis. In particular, worse Psychological well being and Inner experience of disease were associated with higher levels of anxiety and depression, and minor Role/sociability was associated with poorer cognitive and physical performances, in line with the role played by these abilities and the emotional impact of the disease in daily life. These findings, together with a high internal consistency (an $\alpha$ value of 0.91 ), confirm the accuracy and reliability of the FLIC in exploring QOL in patients with recurrent glioma, in line with the results of previous studies in patients with different brain tumours. ${ }^{915}$

It is worth noting that the psychosocial themes represented a major component of QOL in patients with glioma, although the subjective perception of overall well being was also related to objective cognitive and physical functioning. In addition, the Isolation/sharing factor did not relate to other scale or test scores, or to the indices of disease severity and progression, suggesting that this factor is a primary psychological facet (an original individual theme that bears personal meanings), rather than a mere sum of performance and disease related factors. These findings suggest that, in 
patients with glioma, disease severity does not necessarily prevent the expression of personal feelings, and are in line with the observations that brain damaged patients may express various subjective definitions of QOL because each person attributes a unique meaning to his/her QOL. ${ }^{39}$ Accordingly, previous studies also showed that, in life threatening situations, patients' points of view, personal feelings, and core meanings can influence clinical outcome and coping. ${ }^{40} 41$

Our patients with grade IV glioma had lower perceived global QOL levels and physical and attention performances than those with grade III glioma. This may be because the patients with grade IV glioma were older than those with grade III glioma, and because clinical worsening was faster after the recurrence of grade IV glioma. Histology, age, and performance status are important prognostic indices for survival in patients with recurrent glioma. ${ }^{42}$ Furthermore, in patients with non-recurrent glioma, the better QOL associated with grade III glioma parallels longer survival, which is a well known consequence of histological grading and age effects. ${ }^{37}$

Re-operation did not lead to a difference in the QOL, although the re-operated patients survived longer, were younger, and had a higher educational level than those who underwent one operation only. This lack of difference in QOL cannot reflect the overlapping effects of combined treatments because all of our patients had undergone both radiotherapy and chemotherapy after surgery, thus suggesting that repeated operations may allow longer survival without improving the QOL.

The lack of a difference in QOL between patients with different tumour locations may depend on the fact that tumour recurrence and the multiple treatments prevent specific brain behaviour correlations.

As expected, our patients with glioma were significantly more anxious and cognitively impaired than the healthy subjects. However, it is worth noting that depression was not significantly worse in the two latest disease epochs (six months after recurrence) in comparison with the healthy subjects. The similarity of this result with those of a previous study showing considerable anxiety and depression in the early stages of disease ${ }^{9}$ suggests that mood may worsen soon after both the diagnosis of disease recurrence and the initial communication of a tumour diagnosis, because both situations are very stressful. When combination treatments are planned and patients enter serial hospital procedures thinking that something can still be done, renewed hope, feelings of protection, and emotional adaptation may contribute towards improving mood. The preservation of a good mood more than six to 12 months after glioma recurrence may be explained by the maintenance of a stable QOL, which did not worsen in subsequent epochs or, alternatively, an acceptable QOL may be explained by a preserved mood. In any case, these findings suggest that QOL and mood are coherent factors that do not necessarily worsen after disease recurrence. The perceived QOL and mood of our patients with brain tumours were not different from those of the patients with other chronic diseases, thus suggesting that their subjective perspective is not necessarily worse than that of patients with different disabling diseases. Conversely, the greater attention impairment of patients with glioma supports the hypothesis that cognitive impairment is an outstanding sign of patients with brain tumours, and constitutes a main domain of their QOL. ${ }^{6} 9^{15}{ }^{38}$ In addition, the results of the regression analysis suggest that the attention deficits may predict the disease duration irrespective of other cognitive deficits, the level of anxiety and depression, physical performance, age, education, and the extent of the initial surgery. The specific involvement of attention in these patients may be related to the histological features and growth of the lesion: tumour infiltration through surrounding brain areas and mass effects on distant structures can cause dysfunction of widespread neuronal pathways, such as those involved in the attention system. ${ }^{43}$ In addition, a slowly progressive tumour growth may allow the preservation of some of the cognitive functions related to the site of the tumour. ${ }^{44}$ Our findings support those of Meyers et $a l,{ }^{18}$ and indicate that the predictive role of verbal memory deficits on patients' survival, irrespective of clinical, histological, and surgical variables, may result from the fact that memory functions also involve widespread neuronal pathways. Taken together, these data confirm that attention and memory deficits represent indices of tumour progression, marking both QOL and survival of patients with brain tumours.

The results of our study, in particular the patients' willingness and ability to express their point of view, and the significant influence of mood, cognition, and physical performances on QOL, may have practical implications. Patients can communicate their opinions about the diagnostic and therapeutic course, accepting or refusing to give informed consent, in line with the ethical principle of self determination. Psychological support for patients and families (such as counselling, family groups, self support, etc) could be tailored according to the personal appraisal of QOL, reactions, and strategies of coping. Cognitive and motor rehabilitation could be combined to address the disabilities. ${ }^{45}$ Although these treatments do not necessarily lengthen patients' survival, they could satisfy the psychological needs of the patients and their families, contributing to improve QOL.

In conclusion, the results of our study show that QOL self evaluations and multidimensional assessments are feasible in selected patients with recurrent glioma. Although multiple themes concur in determining the perceived QOL of these patients, psychosocial facets are the strongest determinants. Conversely, clinicopathological variables other than tumour grading do not significantly influence subjective QOL, and the subjective and assessed QOL dimensions are not worse than in patients with other chronic neurological diseases. The results contrast with the expectation of a progressive deterioration in autonomy and awareness after glioma recurrence, suggesting that recurrence does not necessarily eliminate hope or the possibility of expressing personal feelings. Patients' opinions can provide reliable criteria for clinical decision making and psychosocial support.

\section{Authors' affiliations}

A R Giovagnoli, E Colombo, Department of Neurology and Neuropathology, Carlo Besta National Neurological Institute, Via Celoria 11, 20133 Milan, Italy

A Silvani, A Boiardi, Department of Neuro-Oncology, Carlo Besta National Neurological Institute

Competing interests: none declared

\section{REFERENCES}

1 Calman KC. Quality of life in cancer patients - an hypothesis. J Med Ethics 1984;10:124-8.

2 Prados MD, Scott $C B$, Rotman $M$, et al. Influence of bromodeoxyuridine radiosensitization on malignant glioma patient survival: a retrospective comparison of survival from the Northern California Oncology Group (NCOG) and Radiation Therapy Oncology Group trials (RTOG) for glioblastoma multiforme and anaplastic astrocytoma. Int J Radiat Oncol Biol Phys 1998;40:653-9.

3 Sneed PK, Stauffer PR, McDermott MW, et al. Survival benefit of hyperthermia in a prospective randomized trial of brachytherapy boost + hyperthermia for glioblastoma multiforme. Int J Radiat Oncol Biol Phys 1998:40:287-95.

4 Levin VA, Leobel SA, Gutin PH. Neoplasms of the central nervous system. In: De Vita VT Jr, Hellman S, Rosenberg SA, eds. Cancer: principles and practice of oncology, 5th ed. Philadelphia PA: Lippincott-Raven, 1997:2022-8. 
5 Mackworth N, Fobair P, Prados MD. Quality of life self-reports from 200 brain tumor patients: comparison with Karnofsky performance scores. J Clin Oncol 1992; 14:243-53.

6 Giovagnoli AR, Boiardi A. Cognitive impairment and quality of life in longterm survivors of malignant brain tumors. Ital J Neurol Sci 1994;15:481-8.

7 Taphoorn MJB, Schiphorst AK, Snoek FJ, et al. Cognitive functions and quality of life in patients with low-grade gliomas: the impact of radiotherapy. Ann Neurol 1994;36:48-54.

8 Murray KJ, Nelson DF, Scott C, et al. Quality-adjusted survival analysis of malignant glioma. Patients treated with twice-daily radiation (RT) and carmustine: a report of Radiation Therapy Oncology Group (RTOG) 83-02, Int J Radiat Oncol Biol Phys 1995;31:453-9.

9 Giovagnoli AR, Tamburini M, Boiardi A. Quality of life in brain tumor patients. J Neurooncol 1996:30:71-80.

10 Weitzner MA, Meyers CA, Byrne K. Psychosocial functioning and quality of life in patients with primary brain tumors. J Neurosurg 1996;84:29-34.

11 Choucair AK, Scott C, Urtasun R, et al. Quality of life and neuropsychological evaluation for patients with malignant astrocytomas: RTOG 91-14. Int J Radiat Oncol Biol Phys 1997:38:9-20.

12 Jason GW, Pajurkova EM, Taenzer PA, et al. Acute effects on neuropsychological function and quality of life by high-dose multiple daily fractionated radiotherapy for malignant astrocytomas: assessing the tolerability of a new radiotherapy regimen. Psychooncology 1997:6:151-7.

13 Newton HB, Malkin MG. Ethical issues in neuro-oncology. Semin Neurol 1997; 17:219-26.

14 Osoba D, Aaronson NK, Muller M, et al. Effect of neurological dysfunction on health-related quality of life in patients with high-grade glioma. J Neurooncol 1997:31:263-87.

15 Giovagnoli AR. Quality of life in patients with stable disease after surgery, radiotherapy, and chemotherapy for malignant brain tumor. J Neurol Neurosurg Psychiatry 1999;67:358-63.

16 Weitzner MA. Psychosocial and neuropsychiatric aspects of patients with primary brain tumors. Cancer Invest 1999;17:285-91.

17 Shrieve DC, Gutin PH, Larson DA. Central nervous system toxic effects of radiotherapy. In: Berger MS, Wilson CB, eds. The gliomas. Philadelphia, PA WB Saunders Company, 1999:737-40.

18 Meyers CA, Hess KR, Yung WK, et al. Cognitive function as a predictor of survival in patients with recurrent malignant glioma. J Clin Oncol 2000; 18:646-50.

19 Osoba D, Brada M, Prados MD, et al. Effect of disease burden on healthrelated quality of life in patients with malignant gliomas. Neurooncology 2000;2:221-8

20 Armstrong $\mathrm{CL}$, Hunter JV, Ledakis GE, et al. Late cognitive and radiographic changes related to radiotherapy. Neurology 2002;59:40-8.

21 Pelletier G, Verhoef MJ, Khatri N, et al. Quality of life in brain tumor patients: the relative contributions of depression, fatigue, emotional distress, and existential issues. J Neurooncol 2002;57:41-9.

22 Brada M, Yung WKA, Osoba D. Symptom burden in patients (PTS) with recurrent high-grade gliomas [abstract]. Proceedings of the American Society of Clinical Oncology 1999;18:147a.

23 Yung WK, Prados MD, Yaya-Tur R, et al. Multicenter phase II trial of temozolomide in patients with anaplastic astrocytoma or anaplastic oligoastrocytoma at first relapse. Temodal Brain Tumor Group. J Clin Oncol 1999; 17:2762-71.
24 Dinnes J, Cave $C$, Huang $S$, et al. A rapid and systematic review of the effectiveness of temozolamide for the treatment of recurrent malignant glioma. Br J Cancer 2002;86:501-5.

25 Salander $\mathbf{P}$, Bergenheim T, Henriksson R. How was life after treatment of a malignant brain tumor? Soc Sci Med 2000;51:589-98.

26 Costain KC, Hewison J, Howes M. Comparison of a function-based model and a meaning-based model of quality of life in oncology: multidimensionality examined. Journal of Psychosocial Oncology 1993;1 1:17-35.

27 Salander $\mathbf{P}$, Karlsson T, Bergenheim T, et al. Long-term memory deficits in patients with malignant gliomas. J Neurooncol 1995;25:227-38.

28 Karnofsky DA, Burchenal JH. The clinical evaluation of chemotherapeutic agents in cancer. In: McLoad CM, ed. Evaluation of chemotherapeutic agents. New York: Columbia University Press, 1949:191-205.

29 Schipper H, Clinch J, McMurray A, et al. Measuring the quality of life of cancer patients: the functional living index-cancer: development and validation. J Clin Oncol 1984;2:472-83.

30 Spielberger CD. Inventario per l'ansia di stato e di tratto. Manuale. Firenze: Organizzazioni Speciali, 1989.

31 Zung WWK. A self-rating depression scale. Arch Gen Psychiatry $1965 ; 12: 63-70$.

32 Katz S, Downs TD, Cash HR, et al. Progress in development of the index of ADL. Gerontologist 1970;10:20-30.

33 Basso A, Capitani E, Laiacona M. Raven's coloured progressive matrices: normative data on 305 adult normal controls. Functional Neurology 1987;2:189-94.

34 Spinnler H, Tognoni G. Standardizzazione e taratura italiana di test neuropsicologici. Ital J Neurol Sci 1987;6(suppl 8):47-50

35 Lezak M. Neuropsychological assessment. New York: Oxford University Press, 1995.

36 Novelli G, Papagno C, Capitani E, et al. Tre test clinici di memoria verbale a lungo termine. Taratura su soggetti normali. Archivio di Psicologia Neurologia e Psichiatria 1986;47:278-96.

37 Brada M, Yung WK. Clinical trial end points in malignant glioma: need for effective trial design strategy. Semin Oncol 2000;27(suppl 6):11-19.

38 Weitzner MA, Meyers CA. Cognitive functioning and quality of life in malignant glioma patients. Psychooncology 1997;6:169-77

39 Fox S, Lantz C. The brain tumour experience and quality of life: a qualitative study. J Neurosci Nurs 1998:30:245-52.

40 Salander P, Bergenheim T, Henriksson R. The creation of protection and hope in patients with malignant brain tumors. Soc Sci Med 1996;42:985-96.

41 Mueller PS, Plevak DJ, Rummans TA. Religious involvement, spirituality, and medicine: implications for clinical practice. Mayo Clin Proc 2001;76:1225-35

42 Rajan B, Ross G, Lim C, et al. Survival in patients with recurrent glioma as a measure of treatment efficacy: prognostic factors following nitrosourea chemotherapy. Eur J Cancer 1994;12:1809-15.

43 Van Zomeren AH, Brouwer WH. Clinical neuropsychology of attention. Oxford: Oxford University Press, 1994

44 Anderson SW, Damasio H, Tranel D. Neuropsychological impairments associated with lesions caused by tumor or stroke. Arch Neurol 1990;47:397-405

45 Huang ME, Wartella JE, Kreutzer JS. Functional outcomes and quality of life in patients with brain tumours: a preliminary report. Arch Phys Med Rehabil $2001 ; 82: 1540-6$ 